\title{
Family Systems Approach to Sexual Dysfunction in Neurologic Disability
}

\author{
Martha K. Stavros, MSW, ACSW, BCD
}

The treatment of sexuality issues among the disabled is improved by the use of tools drawn from the Family Systems Model. The systems perspective lends an overview of the unique meaning of sex to the individual client as he or she has learned it in the context of the family. The construction of a genogram and an ecogram "map" the psychosexual patterns that are affected by the onset of a disability, suggesting treatment that exactly matches the needs of the persons involved. Use of the model is beneficial for many other reasons than the increased effectiveness of treatment, however. It is faster and more effective than many other modalities. It is a good tool for training teams to better understanding their own family sexuality messages. Lastly, "picturing" of the issues supports the development of research and therefore resources for the treatment of sexuality matters among the disabled.

KEY WORDS: systems; sexuality; disability.

To effectively rehabilitate a person who has experienced changes in his or her sexual function due to injury or disease it is necessary to understand the idiosyncratic meaning of the changes to the individual and to those with whom he or she relates. A sensitive assessment of both the real and the perceived alterations in life experience of the unique human being and his or her relations because of a neurological insult should precede any involvement by helping professionals. A movement away from a focus on the actual sexual functioning to a view of the whole person in a context is a shift from the medical model to viewing the changes through the perspective of systems.

Before its introduction to the field of mental health, systems theory was applied to the fields of business and technology. Because it developed into a

'Senior Clinical Social Worker, Adult Rehabilitation Services, University of Michigan Hospitals, Ann Arbor, Michigan 48109. 
careful study of the complex web of multi-level connections that interrelate to result in a given technological phenomenon, dramatic changes in product management and service delivery throughout the world have been possible. In $A$ Systems Approach to Organizational Renewal, Gordon Lippitt says, "Thinking about an organization as a system helps us accept the human-machine relationship of today's society. All organization systems include in their make-up many elements and processes. This is true for all, including subsystems, the smallest group (or dyad), and the most complex multigroup structures of the international organization. When no attention is paid to the elements and processes of the system, it cannot function effectively" (1).

No less is true of family systems. According to one author, the family is defined as a "self-regulating system which controls itself according to rules formed over a period of time through a process of trial and error. A family works out its own way of being together through interaction and feedback. They have rules about everything. The rules and patterns are peculiar to each family alone and the importance of understanding this is fundamental to being of real help to those have sustained neurological impairments" (2).

Until the introduction of the systems perspective and some easy-to-use tools of that model to rehab teams, it was unthinkable to even try to fully appreciate the meaning and probable impact of problems in sexual function to individual persons treated in our fast-paced medical service delivery systems. With the methods taught by this model, however, it is now possible to assess with some confidence the meaning of sexuality changes to the persons involved and to assist clients to avoid compounding pre-existing problems as a result of a disability. A brief history may be helpful.

The family systems model grew out of the experiences of mental health professionals who worked with returning military persons immediately following the Second World War. At that time, it was common for psychiatrists and psychologists to separate out from their families clients who exhibited adjustment problems of any kind. While social workers offered comfort and encouragement to suffering family members, "therapy" was done to identified client. At first it appeared that the isolation of persons from their families and environment resulted in apparent cures of all sorts of aberrent behavior, but soon it became obvious that the "cures" did not in fact hold up when the disabled persons returned to their support systems. The recidivism problems with alcoholism, obesity and even schizophrenic behavior were dramatic and frustrating examples that proved that the complex interworking of the family is clearly a variable in assessment and treatment (3).

Although it seems impossible to conceive of in the costly treatment facilities of today, early investigators into the contextual approach to understanding behavior actually performed studies that required hospitalization of whole families! Salvador Minnuchin, for example, found success by hospitalizing entire 
families of clients who suffered from schizophrenia. The effect of treating whole networks was dramatic and lasting. The common sense notion that all of the players in a person's family affect his or her behavior supported the development of a whole new body of research and literature that sees clients in the context of two or three generations of family roles and values (4). Very quickly thereafter the tie between the family system and sexuality issues was established as well. Hoff and Berman, who authored "The Sexual Genogram," are examples (5).

The systems perspective has changed all approaches to mental health issues. In the area of sexuality, the recent decades have greatly enriched our understanding of the factors that influence the selection of sex partners and mates. It has been established that a person absorbs his or her sexual identity and role assignments in a family context. Not only are values, mores, attitudes, and perceptions "ingested" as it were on an unconscious level in a family but so are messages about what one has to do to be loved. Correctly or incorrectly, children master behaviors that gain for them the attention they need to survive in their own families of origin. These become personality patterns. Solidly grounded on needs, these "hungers" are expressed in each choice an individual makes for his or her entire life, but most emphatically in sexual choices. Sex becomes a vehicle for expressing the unfinished "stuff" of parental relating. Because these patterns are intrinsically bound to ego development, they are fiercely protected by emotions that are so strong that they often supercede intellect, i.e., "I would rather die than be without him." This, of course, is the grist of the well established literature of co-dependence.

The importance of understanding the individualized perception of reality to our treatment of sexuality of the disability and make up the carefully guarded identity issues predictably become exaggerated under stress. In crisis, persons seem to retrench to the basic primitive messages of their elementary experience. They become more of what they are. The indelible dyes of the personality, that which is underneath the visible public person who appears in the less stressed forums of everyday life, perform as though on cue. James Allen says rightly, "Circumstances do not make a man, they reveal him" (6).

The fact is, sexual behavior of any kind can be explained within the matrix of a person's social system. To a greater or lesser extent it is a reliance on someone else to get unmet needs filled, to avoid fear or emotional pain, to solve problems, and to maintain balance. Sexual relating is unconsciously perceived as one way to gain control over one's life (7). Learned very early in the emotional climate of the family, it is fiercely defended as "normal" no matter how it might be viewed by outsiders. From a family systems perspective, even deviant behavior such as rape, incest, and abuse can be viewed as adaptive within its own context. Aberrant behavior appears understandable from the viewpoint of those concerned. 
This deeply ingrained system of sexual attitudes and behavior cannot be ignored when treating clients who have sustained neurological impairments. In fact, the identification of the contextual meaning of sexual dysfunction for the disabled is clearly an important addition to the understanding of physiologic changes. Furthermore, to effectively "treat" the individual, losses and changes due to the disability need to be understood within a family and social system. We have to know what our patients value in order to understand what they have lost.

The systems model espouses the use of two tools that greatly facilitate the assessment of these complex and yet fundamental family systems patterns. These tools employ a few simple and easy to use symbols that make up two graphs: a genogram and an ecogram (Fig. 1).

The genogram is a simple-to-construct map of family relationships and patterns over three generations. Hoff and Berman say, "The genogram is, basically, a three-generational diagram, or map, of the people who make up one's family. It can include whatever data the therapist wishes. At the minimum, births, deaths, marriages and divorces . . . it casts a wider net by including everyone; not only those clients seen as important. It is more apt to reveal emotional cut-offs, secrets and previously unnoticed alliances . . ." (8).

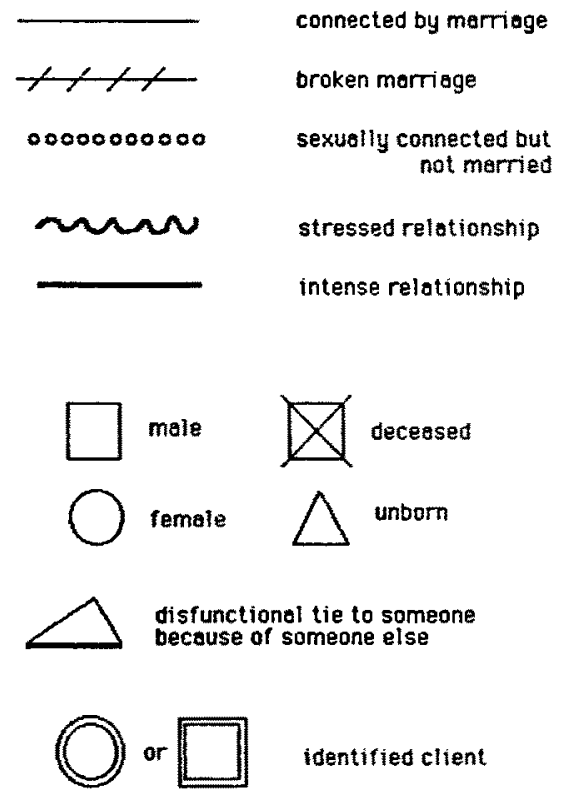

Fig. 1. Simple symbols. 
The ecogram, using the same symbols, displays the family as it exists in the wider milieu of the society around it (9).

The advantages of using these tools are many. Constructing a visible graph that families actually help to create is in itself a therapeutic experience. A client who assisted in the "mapping" of her family's genogram just after her headinjured husband was accepted into an inpatient rehab setting was heard to remark when she looked at the finished genogram that she had never really thought about how chaotic her spouse's family of origin had been. Nor had she wondered before making the genogram what had attracted her to so much agony.

The experience of making a genogram allows the persons involved to have their first objective look at the reasons they do what they do. The creation of an ecogram, on the other hand, visually displays the support systems or the client's pattern of alienation. It also clarifies the resources that may be mobilized for help. For the treatment team, the visibility of the genogram and ecogram offers a vastly improved appreciation of the family patterns that support sexuality concerns. Taking the time and effort to follow the diagrams to identify the patterns in a few case examples will illustrate their effectiveness (Fig. 2).

In the case of Mr. P., the genogram reveals quickly that he was 43 years old when he sustained a severe left CVA. The patient's wife had been asked to talk about the family by a social worker who encouraged her to understand that no one experiences loss in just the same way as anyone else. To reduce the possibility that she would feel the interviewer was asking too many sensitive questions, Mrs. P. was assured that each family is unique, "special," and would be seen that way by the treating team. The genogram that was sketched during the interview clearly revealed the following important facts relevant to sexuality.

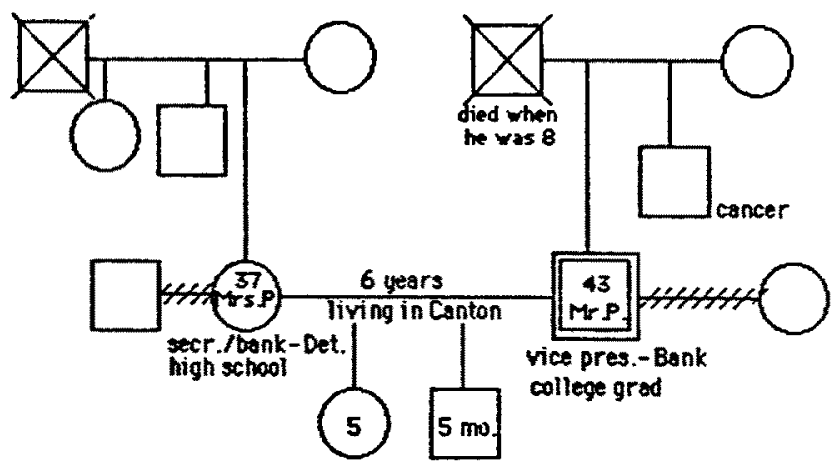

Fig. 2. Mr. P., 43 year old male with a left CVA. 
The broken lines indicate that Mr. P. and his wife had each been married before, unhappily. They had married each other only six years before his stroke. It shows that he is a first born in a family in which the father had died when Mr. P. was eight years old. Presently, his only brother has cancer. Mr. P. is shown to be a bank vice-president, and oldest son, an "in-charge person." His wife, on the other hand, is the youngest in a family that includes two older siblings. She too has a widowed mother but she hasn't had the "in-charge" assignment her husband has had. The display goes on to show that she does not have a college education while Mr. P. does. She, in fact, has been a secretary in the same bank at which he is the vice-president. The couple have two little children and live in an expensive suburb that suggests, at this early stage of their marriage, they may be financially extended. Their home is located far enough from the treating hospital so as to clearly be a major commute for the wife.

To the information gleaned from the genogram are added the facts of profound aphasia and complete dependence for all A.D.L.'s, including bowel and bladder, to explain the impact this disability is going to have on this man's ego. Depression is predictable and it is obvious that the effects on Mr. P.'s sexual functioning go beyond the facts of his organic limitations. His wife is doubtlessly overwhelmed, but she is also angry. The reasons for her attraction to this apparently strong protector-type have gone down with his disability. She is exhausted driving miles every day, caring for two babies, short of money, and being the caretaker for the partner she unconsciously needed to take care of her. Her needs are clearly not being met. There is the possibility that she will experience guilt because she has needs in the face of her husband's dependence. Furthermore, the repressed rage will color the home environment in which the little children will get their education in sexuality.

The information gathered about Mr. P. is psychosocial. It does not replace the medical work-up nor the sexual history. It is the contextual explanation of the sexual relating underpinning the marriage before the disability. It is, therefore, the best indication of the needs of both of the individuals concerned as well as his and her well-practiced ways of filling them. When the disability interrupts this process, the frustration and loss to the individual require understanding and help from competent professionals.

Because the genogram lends itself to unusually accurate assessment, it is the springboard of good treatment planning. Consider the case of Karen, a 35 year old female with severe multiple sclerosis (MS) (Fig. 3).

Karen's husband, the genogram shows, is the oldest child in a family that includes both alcohol and physical abuse by the father. He had four younger siblings when his father abandoned the family leaving him as the parentified child, the surrogate spouse to his mother with whom he still maintains a close tie. (Note the intense line between the patient's husband and his mother.) The 


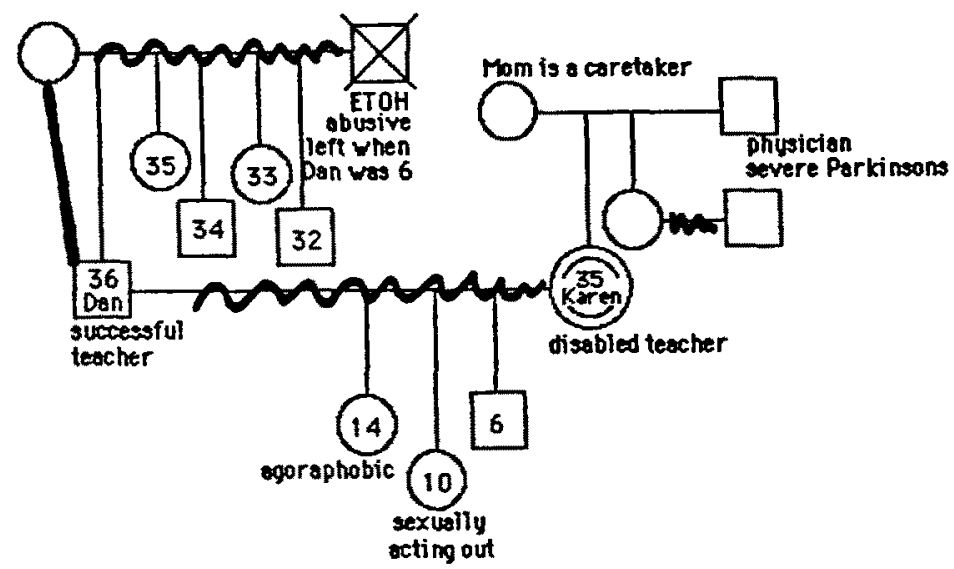

Fig. 3. Karen, 35 year old female, multiple sclerosis.

map shows that the man's experience as a small child supported his becoming overly responsible yet undoubtedly hungry for the mothering that he never received because his mother was his peer and because she had many other children under circumstances that obviously demanded her time.

He had met and married Karen when he was very young. Her family system appears to look like an opposite piece in a puzzle for she is the oldest of two girls. Her mother models caretaking - we see that she is the care provider for her own disabled husband. Her parents have a stable marriage built on clear role assignments. It appears that one "rule" in this family is to stay in a marriage relationship. The genogram shows that Karen's sister is unhappy in her relationship but she remains married. As the oldest girl in this family system, Karen's female role assignment was to be a nurturer. She not only attracted a husband with nurturing needs but she has three children to nurture as well. Both Karen and her husband are teachers, suggesting that without the MS Dan may have had the financial security he missed in his family of origin.

The disease has frustrated them both. Dan, for his part, has to be angry about his wife's dependence and about her inability to earn money. He had wanted a mother and needed security. He has severe Oedipal issues that would support abuse in any case, but surely they fire his anger and frustration in the situation of his wife's disability. Unable to perform even very personal tasks such as toileting without help, Karen is certainly experiencing feelings of worthlessness which will be "functionally" reinforced if he abuses her. The children, experiencing their parents' anger and frustration, are already acting out. The genogram shows that the oldest is agoraphobic and obsessive-compulsive. The second is so age-inappropriate in her seductive behavior that she is in 
treatment with the school social worker. The little boy, as his dad, has so little attention from his mom and such poor modeling from his father that he may predictably model abusive behavior.

It is clear that the genogram has exposed sexuality issues that are exacerbated by the disability. Before the onset of the MS this family was "functionally dysfunctional"; everyone in it was getting what their inner model of themselves perceived as "normal." After the onset of the disease, the system became exaggerated and acts as an incubator for serious sexual dysfunction. To avoid psychosexual problems for generations to come, referrals had to be made and monitored carefully.

Ecograms are maps of the family as it exists in time and space of the larger community. They vividly display the connectedness as well as the alienation that results from a disability. They are useful tools that identify the complex societal contributions to sexuality issues. They suggest treatment as well (Fig, 4).

The ecogram on the case of Karen reveals she is quite unconnected to any outside supports other than the hospital. Her angry and abusive husband is doing everything for her and for the children. He is also working and staying close to his own mother while Karen's parents have not been allowed in to help her. A rearrangement of resources for Karen is apparent from the post-hospital ecogram (Fig. 5).

The patient's family of origin has been recruited to purchase a new home for Karen. The application for social security and the payment for a housekeeper by the parents have underscored new independence which will support higher self-esteem and eschew the possibility of abuse by the spouse. Karen has been supplied with a medical social worker who will oversee the patient's situation and monitor the welfare of the children who should be less stressed under safer circumstances. It is likely that the sexual acting out of the young women will be eliminated and the young boy will not see abuse modeled by his father.

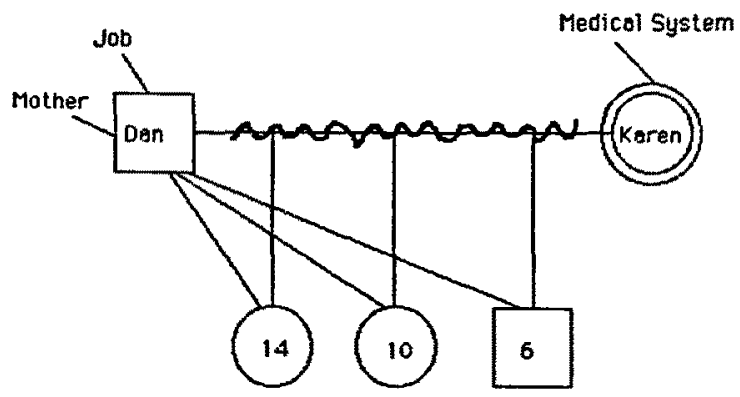

Fig. 4. Ecogram of Karen before treatment. 


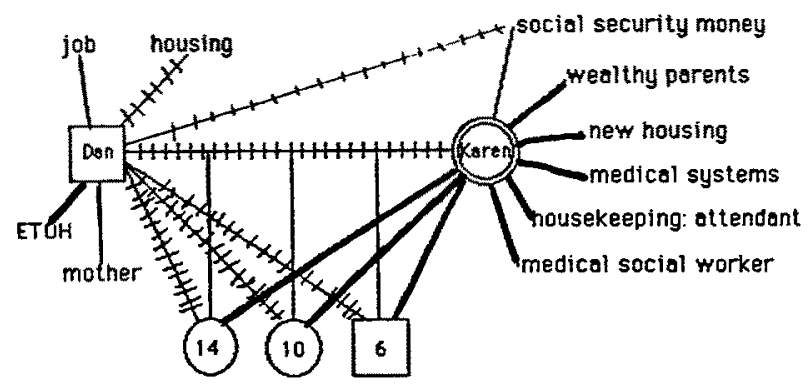

Fig. 5. Ecogram of Karen after treatment.

In another case in which a 41 year old male sustained a severe head injury in a drunk driving accident, the genogram offered visible evidence of the problems that had to be overcome if the disability was not to ruin a marital relationship and destroy a child who could not effectively develop the ego strength she needs to have her own successful partnerships someday (Fig. 6).

The head injury survivor in this case was the only child in the first of his mother's three marriages. He had had an alcoholic father who abused both him and his mother. The mother had had many other children in a second marriage and, at the time of the accident, one was only 20 and still living with her. It is notable that the identified client did not become a parent until he was 37 , and it seems fair to suspect that he wanted too much parenting himself to have had children earlier.

The client's wife, for her part, was an only child of a dad who drank and beat her. The patient's marriage was not doing well before his accident. In fact, the genogram reveals the patient had had a lover on the side. The head injury that reduces his judgment and impulse control bodes ill for this marriage. It is not unlikely he will beat his wife and perhaps the child as well. Because of the head injury he will be even less likely to be discreet in his extramarital relating. Alcohol abuse is predictable and, although there is no history of sexual abuse, this too could easily become a factor.

In Fig. 7, a somewhat more complicated genogram shows us John, who was a 21 year old high school dropout engaged to marry his 17 year old girlfriend at the time he was struck by a tree he was felling. John was in a coma for three days and in the hospital for 17 weeks (10).

The graph shows a history of unstable relationships in his family for generations. The patient was six when his parents divorced. His mother (Janice) had had another son by a previous marriage and she never knew her own father. Her two half-brothers are alcoholics and her mother had been killed in a car accident in 1986, the same year she and her present lover lost their unborn 


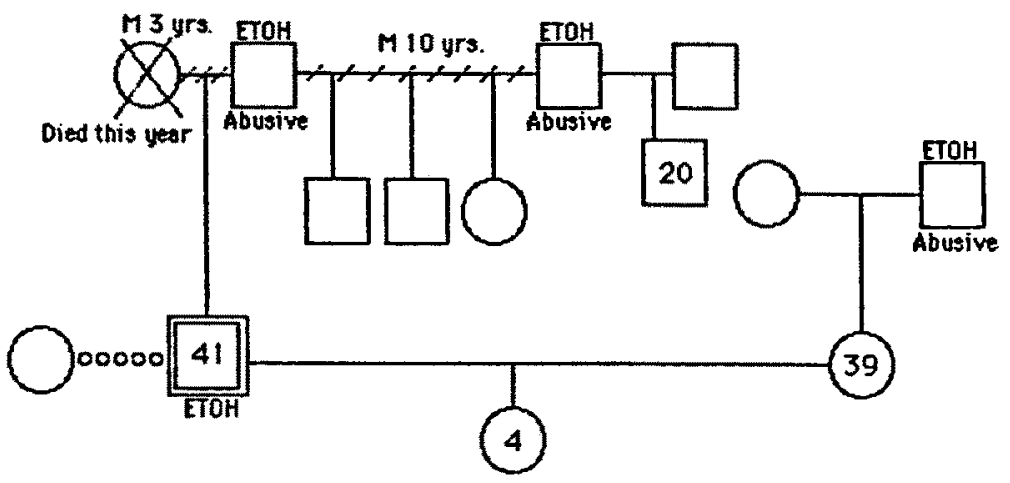

Fig. 6. 41 year old male, head injury.

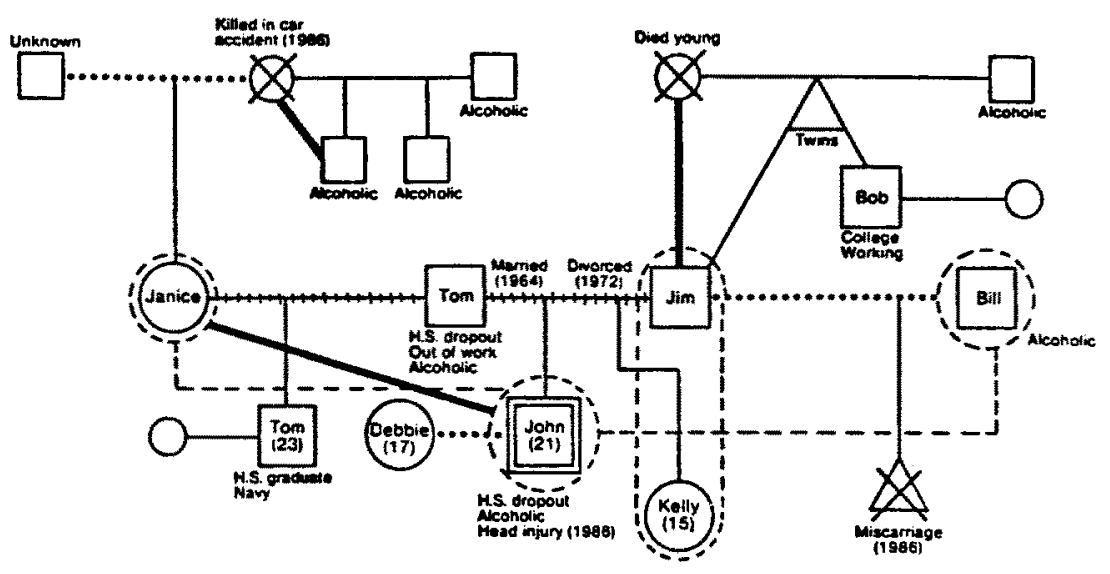

Fig. 7. John, 21 year old male, head injury.

child. John's father, Jim, wasn't a strong male role model for John because he had no male model himself. Jim had been tied to his mother, a pattern repeated between John and Janice and between Janice's brother and his mother as well. The sibling patterns in two generations are visible on the graph. John's dad had a twin (Bob) who was successful enough in Jim's mind to underscore Jim's own dysfunctional life experience. The patient has a half-brother who, at the time of the accident had finished school, married, and joined the Navy, setting John up for a comparison that supported his low self-esteem even before a head injury. John's mother had never had much parenting. In fact, it is likely she 
was the parentified child in an alcoholic family. She picked men who needed the love she never got. The female role assignment in this family is that of caretakers. Note, the genogram shows the 15 year old sister of John already caring for her alcoholic father.

John's girlfriend did not wait for him to get out of the hospital. She announced she was pregnant but left rather than stay with John whose head-injury behavior frightened her. The effect was to further reduce John's self-esteem, to cast the pregnant mother into poverty that denied her good prenatal care, and to expose the baby to a life that promised even less stability and hope for solid relational skills than its parents had had (Fig. 8).

The ecogram in Fig. 8 maps John's connections and separations after the accident. He was cut off from his old friends, from his former job, and from the girlfriend who once filled his life. He became totally dependent on his mother whose own tie to her lover was weakened since she had to be absorbed in her son's caretaking. Janice was overwhelmed by her assignment to take care of John. Her ties to her job and to her extended family were reduced. Her lover distanced, intensifying his contact with work and friends at the bar. A fair supposition is that he is threatened by Janice's choice of her son over him. Not only are there severe sexuality issues for the mother and her lover, but the young man hasn't an appropriate sexual partner and his pregnant girlfriend is without the support she needs to have and raise a child.

In this case the post treatment ecogram (Fig. 9) reveals that the mother and her lover were referred to a counselor to explore and perhaps save their relationship. Janice was off-loaded in her care for the head-injured youth by volunteers from a neighborhood organization. Also, John is back in school with

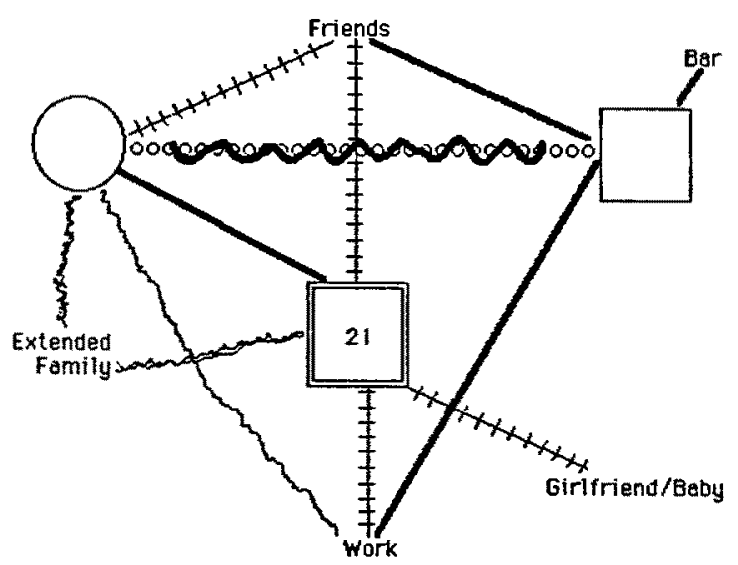

Fig. 8. Ecogram of John before treatment. 


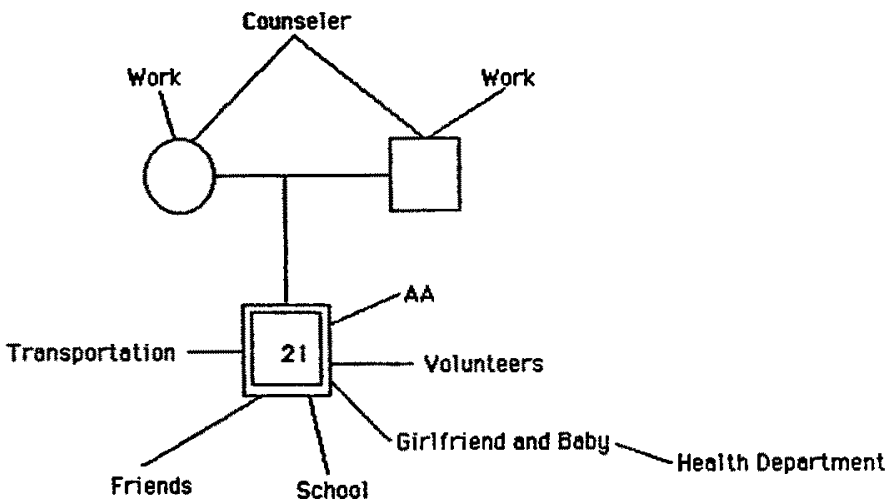

Fig. 9. Ecogram of John after treatment.

transportation arranged under the special education codes at the high school. School contacts have resulted in new friendships and John is actively participating in an AA program. The pregnant girl was contacted and sent to community health services for prenatal care. She will remain in a system that will offer services for children at risk after her baby is born.

The examples offered here are simple for the sake of clarity. The graphs can be far more complex, however. In fact, they often grow as the treating team becomes more familiar with the client. The notation of name similarities may, for example, reveal identifications. On another genogram the mother of a young woman who had tremendous difficulty maintaining heterosexual relationships over time made the comment that she and the child's father had named the girl after his mother who had had similar history. It is not hard to see that their expectations of this child had shaped her sexual behavior from the onset!

Revealing what systems therapists call "dysfunctional triangles" is another function of the diagramming. Bowen points out that two-person relationships tend to be unstable. Too much is expected or emotionally demanded of one person by another so the tendency is to draw in a third, stabilizing the system by forming a coalition, the two being in relationship to the third (11). This serves to take undue pressure off of healthy relationships. It becomes dysfunctional when the third party or thing is drawn in for the purpose of filling the deeply felt emotional hungers of another. A common example is having a baby to relieve the pressure a couple experiences when their relationship no longer seems to fill their needs. The children, as it were, are born with the assignment to provide emotional support for the unfulfilled parents. When persons in such a triangle are suddenly neurologically impaired, complications can be foreseen. 
The genogram in Fig. 10 shows dark lines that highlight the triangles that must be considered in order to understand this family's sexuality issues. In this case a 19 year old man had been assaulted with a tire iron at a rock concert. The genogram shows us that his father (Bill) had been the second son in a family in which the oldest son (his brother) was close to his dad. The closeness of these two set him up to be triangled with his mother, both because she was not getting what she wanted from her spouse and because it met the needs of the little boy who was not preferred by his dad. Bill married a woman (Mary) who had many emotional needs because she came from an unstable home. She triangled with him to get away from her parents. Their marriage produced three sons. The genogram suggests strongly that the emotionally needy mother had triangled her sons one by one, probably supporting her husband's unconscious decision to triangle in his work to reduce the unspoken pressure he experienced from his wife's engulfment.

At the time of the assault the father was traveling, the oldest son had moved out of the home and in with a girlfriend (probably to put distance between himself and the emotional needs of his mother), and the youngest son had died recently in a drowning accident. The effect was predictable. Mary quit her job to take care of the patient (Dan) who had significant cognitive and behavioral residuals from the head injury.

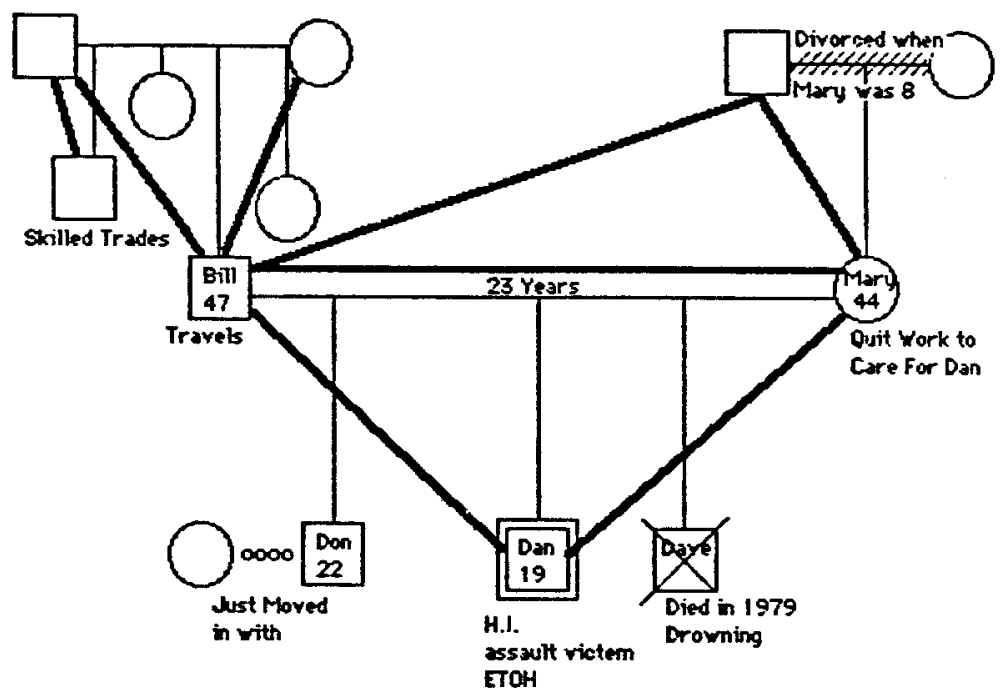

Fig. 10. Dan, 19 year old, head injury. 
In some circles the story would seem to have a happy ending. To the systems savvy, however, it is clear that the mother's own emotional neediness will support the patient's long term dependence. Furthermore, the over-attention to Dan by the mother bodes badly for the parents' marriage. With generations of modeling to do so, the survivor can be expected to respond to his mother's over-closeness by triangling as well. Because this family system uses relationships to reduce felt needs and because the head-injured have great difficulty making and keeping heterosexual ties, he may choose to use prostitutes. In such a case his head injury makes it unlikely he can be counted upon to practice safe sex. Furthermore, his frustration about not being able to find satisfactory sex partners may support his pre-morbid tendency to alcoholism, another well-established pre-morbid family pattern.

Ducharme et al (Sexual Functioning: Medical and Psychological Aspects) explain the characteristics of neurological impairments that complicate sexual functioning. Examples are fatigue, lethargy, impaired judgment, inability to sustain erections, etc. (12). The systems model interprets the impact of the disease or trauma on the individual and the family. It is in the family that the resources to manage stress are developed. It is with family genograms and ecograms that these can most effectively be "read" by treating professionals.

The diagrams give visual emphasis to the fact that all behaviors are a function of complex systems. Interviewing without graphs supports a linear cause-and-effect perspective but the development of displays such as these underscores the complexity of pressures in each individual family. (It is still true that one picture is worth a thousand words.) The effect, of course, is that sensitive assessments lead to treatment modalities that actually work for the persons concerned. In a medical treatment climate that stresses the necessity to provide treatment faster and more effectively than ever before, it is a strong foundation for decision making. Solid knowledge of family systems is also the best substructure for hospital discharge planning, a major focus of the medical service delivery system today. Third party payers are less and less tolerant of discharge plans for patients that result in re-hospitalizations. The use of graphs such as the genogram and ecogram reduces the likelihood of post-hospital failure.

There are several other advantages of the use of systems tools for assisting the neurologically impaired with sexuality concerns. Among these are improved staff training, better education regarding sexuality issues and the disabled, and the development and focusing of resources.

Genograms and ecograms support the understanding that given the same set of circumstances any person would be likely to respond to a crisis in a similar way. Without such a broad view, a negative effect of reviewing case after case of family histories is that treatment teams begin to pathologize families. When at least three generations of a family and the multiple pressures it has endured over time are made visually evident, there is a better chance that 
professionals dealing with it have a healthier and more empathic attitude. It can be said that the team learns that "there are no good guys or bad guys." This is especially useful when treating families which exhibit what might ordinarily be considered aberrant sexual behavior.

Another factor that recommends the use of the systems approach in treating sexuality issues for the disabled is the secondary effect it has on assisting professionals to understand their own family's sexuality patterns. Recurring contact with genograms and ecograms allows therapists to identify the pressures and programs that lead each of them to the place they are in their own lives, both professionally and personally. Deeply rooted prejudices, stereotypes, fears, and unhealthy ties can affect the quality of care a professional is able to offer to the disabled client who has sexuality problems. These are recognized and dealt with when a team member understands his or her own systems. In some instances it is appropriate to actually draw up the genograms of each member of the treatment team so that the advantage of "seeing" one's own system can be experienced and used therapeutically. Murrey Bowen, an important pioneer in training staff in the family systems paradigm, commented about the psychiatric residents with whom he had used the family of origin method to help them see their own family systems. "The resident physicians who had done best in the effort with their parental families . . . were also doing best in their clinical work" (13).

Obviously, the third advantage to treatment personnel who use this ecological approach to assessing and treating sexuality issues for the disabled is the satisfaction that comes with the confidence that the problems are being met effectively. Imposing treatment modalities that may or may not fit the needs of those being served is guess work; whereas, tailoring treatment to clients' needs as they are made evident by systems graphs is likely to work immediately. The validation of the skills of therapists involved increases job satisfaction.

Educational advantages are also served. The systems approach, with its visual tools, is useful for promoting a better appreciation of the unique features of sexuality concerns among the neurologically impaired. It demonstrates visually that this population not only faces the organic problems consistent with each diagnosis, but also these are played out on the backdrop of a family system. Impotence is a huge issue in a system that touts "MACHO" values. Hypersexuality is a source of deeply felt shame for a family that honors control and discipline. Infertility hurts most when the genogram indicates that big families are the largest source of pride to a particular family. The hands-on demands of very personal care are sources of embarrassment and anger in a system that, over the years, has been characterized by careful distances between the sexes in public. Education of team, family members, and even the public is greatly improved when the springboard for teaching is the visible systems map that makes such idiosyncratic truths apparent.

Last, but not least, the advantages of the ecological displays underscore 
the need for the development and focusing of resources. In every area of medical and mental health care the gulf between knowledge and service delivery grows more vast every year that costs rise and resources shrink. It is ironic and painful that more professionals are better trained to effectively assist the neurologically impaired with the important resumption of meaningful sexuality at the same time that less and less of this competence is available to the general public. It is hopeful that, in today's climate of ecological sensitivity to the Earth, more people than ever can understand the lessons offered by the systems approach to the treatment of this client population. The impressive visual quality of the genogram and ecogram signify both the needs and the paucity of services that actually trickle down to the hurting families. At the same time, they dramatically underscore the impact of ignoring the issues over time.

Much more could be said to support the use of systems tools to better understand the neurological event on the sexuality of the persons involved. The preceding is very simplified to make the point regarding the value of the systems approach. Little has been written to directly link the tools to the care of the neurologically disabled but much of the systems studies can be generalized. Duane Bishop, M.D., has developed a comprehensive bibliography that reflects much research that can be applied (14). Monica McGoldrick and R. Gerson authored a text called Genograms in Family Assessment that demonstrates the development of the graphs in very sexually complex family systems. The latter is a highly readable teaching tool for helping personnel who want to learn to create the maps to assist their own clients (15).

It is clear to most concerned professionals that many families are in quite enough pain when the additional burden of a neurological insult catapults them into near despair. For each, the event's consequences touch on sexuality because in every case self-esteem and the essential meaning of life are taxed. In this paper it has been shown that each family system has its own way of reasserting balance under stress. The methods are not always functional nor do they often work under the new circumstances of the disability. Having "seen" the patterns over several generations of time, however, the thoughtful therapist abstracts from the well practiced family dance the intention of the behaviors and enables the client to find a new and, in some cases, healthier way to achieve the same ends.

\section{REFERENCES}

1. Lippitt G: A systems approach to organizational renewal. In Organizational Renewal: A Holistic Approach to Organizational Development. New York, Prentice Hall, 1982

2. Palazzoli M, et al: Paradox \& Counterparadox. New York, Jason Aronson, 1978

3. Hartman A: University of Michigan Graduate School Lecture, 1979

4. Guerin PJ: Family therapy: the first twenty-five years. In Family Therapy: Theory \& Practice. New York, Gardner Press, 1976 
5. Hoff L, Berman E: The sexual genogram. J Mar Fam Ther 12(1):39-47, 1986

6. Allen J: As a Man Thinketh. New York, Putman Press, 1959

7. Schaeffer B: Is It Love or Is It Addiction?. New York, Harper \& Row, 1988

8. Hoff L, Berman E: The sexual genogram. J Mar Fam Ther 12(1):39-40, 1986

9. Hartman A: University of Michigan Graduate School Lecture, 1979

10. Stavros M: Using family assessment tools to improve discharge planning for the traumatically brain injured. Rehab Report 4-6, November 1988

11. Bowen M: Theory in the practice of psychotherapy. In Family Therapy: Theory \& Practice. New York, Gardner Press, 1976

12. Ducharme S, Gill K, Biener-Bergman S, et al: Sexual functioning: medical \& psychological aspects. In Rehabilitation Medicine: Principles \& Practice. Philadelphia, Lippincott, 1988

13. Bowen M: Family Therapy in Clinical Practice: Collected Papers of Murray Bowen. New York, Jason Aronson, 1978

14. Bishop D: Family therapy in family medicine. Am J Fam Ther $9(2): 12-82,1981$

15. McGoldrick M, Gerson R: Genograms in Family Assessment. New York, WW Norton, 1985 